\title{
Numerical simulation and analysis of the effect of baffle distance and depth on solid-liquid two- phase flow in circular secondary clarifier
}

\author{
Fang $\mathrm{He}^{*}$, Jian Wang, Wei Chen \\ School of Urban Construction, Wuhan University of Science and Technology, Wuhan 430065, China
}

Corresponding Author Email: hefang@wust.edu.cn

https://doi.org/10.18280/ijht.360115

Received: 9 September 2017

Accepted: 21 December 2017

\section{Keywords:}

circular secondary clarifier (CSC), peripheral inlet and outlet (PIO), numerical simulation, velocity field, sludge volume concentration field.

\begin{abstract}
This paper aims to identify the optimal working effect of peripheral-inlet and outlet (PIO) circular secondary clarifiers (CSCs). For this purpose, the simplified multiphase mixture model was adopted for the 2D numerical simulation of hydraulic features of the solid-liquid two-phase flow in CSCs. Specifically, the closed-form time-averaged flow equations were established by the RNG k- $\varepsilon$ turbulence model, the differential equations were discretized by the finite volume method, and the coupling velocity and pressure equations were solved by the pressure-implicit with splitting of operators (PISO) algorithm. Then, numerical simulations were performed to disclose how the retaining baffle-deflection baffle distance and retaining baffle depth influence the distribution of the velocity field and sludge volume concentration field in a PIO CSC. The simulation results show that the optimal performance of the CSC appeared at the baffle distance of $300 \mathrm{~mm}$ and the retaining baffle depth of $600 \sim 1,000 \mathrm{~mm}$. All in all, a proper increase of distance and depth can enhance the sedimentation efficiency and outflow quality, but an excessive increase can only accomplish the very opposite. The research findings provide valuable references to the optimal design of actual secondary clarifiers.
\end{abstract}

\section{INTRODUCTION}

In the design of activated sludge process, the secondary clarifier is the essential final part of the reaction system. The clarifier is responsible for solid-liquid separation of the liquid mixture, and the concentration of sludge. Suffice it to say that the operation of the secondary clarifier directly bears on the treatment effect of the entire system. Currently, the most popular secondary clarifier is the circular secondary clarifier (CSC). There are two main categories of the CSCs, depending on the arrangement of water inlet/outlet: the central-inlet and peripheral-outlet (CIPO) CSC and the peripheral-inlet and outlet (PIO) CSC. As the name suggests, the former has a water inlet at the center and an outlet on the peripheral, while the latter has both water inlet and outlet on the peripheral. In comparison, the PIO CSC boasts many advantages over the CIPO CSC, including but not limited to the long residence time and high sedimentation efficiency. Below is a brief summary of these advantages.

First, high utilization ratio of the CSC volume. The water expands rapidly before entering the PIO CSC due to the long wetted perimeter. The expansion minimizes the inlet flow rate of the clarification area, and thus avoids the flow shortcircuiting of high-speed inlet flow. Second, high sedimentation efficiency. As the water level gradually rises in the PIO CSC, the activated sludge flocculates in the suspension layer. The ensuing collision, adsorption and flocculation among the particles of the activated sludge in the liquid mixture guarantee the good clarification effect. Third, low construction cost. The PIO CSC can achieve the same outlet water quality with half the volume of the CIPO CSC, because its hydraulic (surface) loading rate is twice as high as that of the CIPO CSC.

The PIO CSC has been extensively used in modern wastewater treatment plants (WWTPs). However, the volume and processing capacity of the clarifier depend on various factors, such as solid concentration, circular shape, sedimentation mechanism, inlet/outlet design, baffle position and loading rate, to name but a few. At present, the clarifier design mainly relies on the ideal sedimentation model, failing to consider the effect of the flow regime on sedimentation. To disclose the principles and working conditions of the CSC, it is necessary to investigate the flow laws inside the clarifier. With the maturity of computer technology, the numerical simulation has become the dominant approach of flow field research.

\section{LITERATURE REVIEW}

Recent years has seen numerous studies on clarifies, many of which are grounded on computational fluid dynamics (CFD). For instance, Reference [1] numerically simulates a clarifier at different particle diameters and volume fractions, aiming to identify the effect of the secondary phase (particles) on the primary phase (fluid); the dynamics and flow regime of the clarifier was simulated by a 3D numerical model, considering the momentum exchange between particle phase and fluid phase.

Following a multiphase CFD, Reference [2] simulates the dynamics and flow regime of a rectangular clarifier for potable water, investigates the momentum exchange between the primary phase (liquid) and secondary phase (particles) through two-way coupled calculation and Lagragian discrete phase 
modelling. Through the simulation, the contours, velocity and concentration of stream function were presented, together with the velocity and concentration profiles of inclined tube settlers. The results show that the lamellar tube settlers can change the flow field and enhance the sedimentation efficiency by $20 \%$ compared to the conventional design. Reference [3-4] develops a new settling velocity model based on state-of-theart models for settling velocity and verifies it with activated sludge samples from two WWTPs diluted to different concentrations. Specifically, a 2D axisymmetric CDF model of a CSC was created in light of the new model and validated through full-scale measurements. It is concluded that the compression settling in the CFD model has a direct impact on the sludge distribution in the CSC under dry and wet weather conditions.

Reference [5] highlights the strong correlation between the pseudo-dispersion of the second-order 1D model and relevant boundary conditions, laying the basis for effective simulation of the secondary clarifier in 1D with imposed design and boundary conditions. In light of this, the computing time required to reach the steady state was shortened from several days with the CFD model to a couple of seconds with the iCFD model, while the loss of accuracy was controlled in the acceptable range (the SSRE is $1 / 40.71$ between D0-iCFD and CFD). Reference [6] applies image analysis to sedimentation experiments and proves the feasibility of automatic registration of sludge blanket height. Reference [7] puts forward a new force-based mechanical model for sludge sedimentation. Considering phase interactions, the model describes the sedimentation process with five forces and Newton's law rather than the flux theory. Based on the model, new functions were derived for hydrodynamic drag, solid pressure and shear stress. Then, it is verified that the model can accurately depict the batch and continuous sludge sedimentation process.

Reference [8] creates a 1D model for the sedimentationcompression-dispersion process in the secondary clarifier, and expresses the process as a nonlinear, strongly degenerate, parabolic partial differential equation (PDE) with spatial discontinuous coefficients. Reference [9] investigates the sensitivity of WWTP model performance to the first- or second-order mathematical structure of 1D secondary clarifier models. For this purpose, a global sensitivity analysis (GSA) was performed on the benchmark simulation model, whose inputs were randomly generated according to the biokinetic parameters in the activated sludge model, the separation parameter in the primary clarifier, and the sedimentation parameters in the secondary clarifier model. Reference [10] provides the results of a long-term research program on shallow CSCs performance enhancement through the CFD analysis of their internal hydrodynamic processes.

Reference [11] proposes a mathematical model for the secondary clarifier in the WWTP of Sétif, Algeria. In the model, the movement of the sludge blanket is characterized by the solid flux theory and sedimentation velocity. The measured variation of sludge concentration with depths was found to agree well with that predicted by the model in the range of $0.0 \mathrm{~m}$ and $2.5 \mathrm{~m}$. Reference [12] explores the efficiency of the clarifier with inclined tube settlers under different working parameters, and details the structure, function and sedimentation principle of this type of clarifier. Reference [1314] adopts the two-phase mixture model and the realizable k$\varepsilon$ turbulence model to study the solid-liquid two-phase turbulence and sludge concentration distribution in a CSC.
Specifically, the differential equations were discretized by the finite volume method, while the coupling velocity and pressure equations were solved by the pressure-implicit with splitting of operators (PISO) algorithm. Finally, the velocity, the solid distribution, the turbulence kinetic energy and its dissipation rate in the CSC were obtained through simulation.

Reference [15] studies the hydraulic features of the solidliquid two-phase flow of a circular clarifier through 2D numerical simulation of a simplified mixture multiphase model. The effects of inlet vertical baffle on flow field distribution and sludge mass concentration field were investigated, offering a reference for optimization of clarifier design. Reference [16] implements the realizable $\mathrm{k}-\varepsilon$ turbulence model in the 3D numerical simulation of density current evolution regulation under the following working conditions: the inflow water has a different temperature from the water in the clarifier, and the clarifier adopts two kinds of retaining baffles near the inlet respectively for winter and summer.

To sum up, despite the abundant research into the clarifiers, there is limited report on the effect of the retaining baffle of the PIO CSC on the flow field and sludge volume concentration field. To make up for the gap, this paper establishes 2D model for the PIO CSC with different lengths of retaining baffles and carries out numerical simulation of solid-liquid two-phase flow via the FLUENT. Then, the author analyzed the velocity field and sludge volume concentration field of the solid-liquid two-phase flow in the CSC and discussed how the length of vertical retaining baffle affects the efficiency of the clarifier. The research findings shed new light on the optimal design of actual clarifiers.

\section{MATHEMATICAL MODEL}

\subsection{Multiphase flow model}

The object secondary clarifier is responsible for removing small sludge particles that are slightly denser than water. It is generally assumed that the sludge particles follow the water well in the flow field and have no major interference in the flows field. Therefore, the mixture model was adopted for this research. As simplified multiphase flow model, the mixture model is a desirable tool for simulating the flow field in clarifiers, thanks to its simple structure, light computing load and reliable results. With the small spatial scale of local equilibrium, the model was introduced to solve the momentum and continuity of the mixed phase and the volume fraction, slip velocity and drift velocity of the secondary phase.

The continuity equation of the mixture model is:

$$
\begin{aligned}
& \frac{\partial}{\partial t}\left(\rho_{m}\right)+\nabla \cdot\left(\rho_{m} v_{m}\right)=\dot{m} \\
& v_{m}=\sum_{k=1}^{n} \alpha_{k} \rho_{k} v_{k} / \rho_{m} \\
& \rho_{m}=\sum_{k=1}^{n} \alpha_{k} \rho_{k}
\end{aligned}
$$

where $t$ is time; $\rho_{m}$ is the mixture density; $\nabla$ is the Hamiltonian operator; $v_{m}$ is the average mass velocity; $\dot{m}$ is the mass transfer of user-defined mass source; $n$ is the phase number; $\rho_{k}$ is the volume fraction of the $k$-th phase; $\alpha_{k}$ is the 
density of the $k$-th phase; $v_{k}$ is the average mass velocity of the $k$-th phase.

The momentum equation of the mixture model is the summation of the momentum equation of each phase:

$$
\begin{aligned}
& \frac{\partial}{\partial t}\left(\rho_{m} v_{m}\right)+\nabla \cdot\left(\rho_{m} v_{m} v_{m}\right)=-\nabla p+\nabla \cdot\left[u_{m}\left(\nabla v_{m}+\nabla v_{m}^{T}\right)\right] \\
& +\rho_{m} g+F+\nabla \cdot\left(\sum_{k=1}^{n} \alpha_{k} \rho_{k} v_{d r, k} v_{d r, k}\right) \\
& u_{m}=\sum_{k=1}^{n} \alpha_{k} u_{k} \\
& v_{d r, k}=v_{k}-v_{m}
\end{aligned}
$$

where $n$ is the phase number; $p$ is the pressure intensity; $u_{m}$ is the mixture viscosity; $g$ is the acceleration of gravity; $F$ is the body force; $v_{d r, k}$ is the drift velocity of the $k$-th phase.

The slip velocity is defined as the velocity of the secondary phase (p) relative to the primary phase (q): $v_{q p}=v_{p}-v_{q}$

where $v_{q p}$ is the slip velocity; $v_{p}$ is the velocity of the $p$-th phase; $v_{q}$ is the velocity of the $q$-th phase.

Then, the relationship between the slip velocity and the drift velocity can be expressed as: $v_{d r, p}=v_{q p}-\sum_{k=1}^{n} \frac{\alpha_{k} \rho_{k}}{\rho_{m}} v_{q k}$

where $v_{d r, p}$ is the drift velocity of the $p$-th phase; $v_{q k}$ is the slip velocity of the $k$-th phase.

The volume fraction equation of the secondary phase (p) can be derived from the continuity equation of the phase:

$$
\frac{\partial}{\partial t}\left(\alpha_{p} \rho_{p}\right)+\nabla \cdot\left(\alpha_{p} \rho_{p} v_{m}\right)=-\nabla \cdot\left(\alpha_{p} \rho_{p} v_{d r, p}\right)
$$

where $\alpha_{p}$ and $\rho_{p}$ are the volume fraction and the density of the $p$-th phase, respectively.

\subsection{Mathematical turbulence model}

The CSC is a solid-liquid two-phase flow reactor, in which the water flow is coupled with the sedimentation of suspended matter. Inside the clarifier, the water belongs to the turbulent state owing to its large hydraulic radius. Hence, the research into the water must be grounded on the numerical simulation of turbulence. There are many turbulence models, namely, single equation model, two-equation $k$ - $\varepsilon$ model, Reynolds stress model and large eddy simulation. Among them, the standard $k-\varepsilon$ model has been widely adopted for turbulence simulation. Nevertheless, the model does not apply to anisotropic flows like buoyance flow and gravity stratified flow, because of its isotropic assumption of the Reynolds stress components. As a result, many revised $k-\varepsilon$ models have emerged over the years. One of them is the two-equation $k-\varepsilon$ model based on renormalization group (RNG). In this model, the turbulence viscosity is corrected and computing accuracy is enhanced, considering the rotational and swirling flow conditions in the average flow. In this way, the model becomes an excellent choice for handling the near-wall region, and the flows with high strain rate and streamline curvature. Thus, the two-equation RNG $k$ - $\varepsilon$ model was employed to simulate the flow regime in the object clarifier, with the turbulence kinetic energy $k$ and its dissipation rate $\varepsilon$ being two basic unknown terms. Then, the transport equations of the model can be expressed as:

$$
\rho \frac{\partial k}{\partial t}+\rho u_{j} \frac{\partial k}{\partial x_{j}}=\frac{\partial}{\partial x_{j}}\left[\left(\eta+\frac{\eta}{\sigma_{k}}\right) \frac{\partial k}{\partial x_{j}}\right]+\eta_{t} \frac{\partial u_{i}}{\partial x_{j}}\left(\frac{\partial u_{i}}{\partial x_{j}}+\frac{\partial u_{j}}{\partial x_{i}}\right)-\rho \varepsilon
$$

$$
\begin{aligned}
& \rho \frac{\partial k}{\partial t}+\rho u_{k} \frac{\partial \varepsilon}{\partial x_{k}}= \\
& \frac{\partial}{\partial x_{k}}\left[\left(\eta+\frac{\eta_{t}}{\sigma_{\varepsilon}}\right) \frac{\partial \varepsilon}{\partial x_{k}}\right]+\frac{c_{1} \varepsilon}{k} \eta_{t} \frac{\partial u_{i}}{\partial x_{j}}\left(\frac{\partial u_{i}}{\partial x_{j}}+\frac{\partial u_{j}}{\partial x_{i}}\right)-c_{2} \rho \frac{\varepsilon^{2}}{k}
\end{aligned}
$$

where $u_{i}$ is the time-averaged velocity component along the direction $i$;

$x_{i}$ is the space coordinate along the direction $i$;

$x_{j}$ is the space coordinate along the direction $j$;

$\eta$ is the viscosity coefficient;

$\eta_{t}$ is the turbulence viscosity coefficient;

$\sigma_{k}=0.7179$;

$\sigma_{\varepsilon}=0.7179$;

$c_{1}=1.42-\frac{\tilde{\eta}\left(1-\tilde{\eta} / \tilde{\eta}_{0}\right)}{1+\beta \tilde{\eta}^{3}} ;$

$\tilde{\eta}=S k / \varepsilon$

$S=\left(2 S_{i, j} \times S_{i, j}\right)^{1 / 2}$

$\tilde{\eta}_{0}=4.377$;

$\beta=0.012 \sim 0.015$;

$S_{i, j}=\frac{1}{2}\left(\frac{\partial u_{i}}{\partial x_{j}}+\frac{\partial u_{j}}{\partial x_{i}}\right)$;

$c_{2}=1.68$.

\subsection{Model discretization and numerical solution}

The above differential equations form a closed-form equation set for solving the distribution law of the flow field. The differential equations were discretized under the controlled volume by the finite volume method, the coupling velocity and pressure equations were solved by the PISO algorithm, the volume fraction equation was solved by the first-order upwind scheme, while the momentum, turbulence kinetic energy and its dissipation rate were solved by the second-order upwind scheme. In light of the actual conditions of the CSC, some boundary conditions were applied to find the steady-state solution to the equation set.

\section{STURCTURE AND CONDITIONS OF THE SIMULATION OBJECT}

\subsection{Structure of the CSC}

The CSC is a circular-shape reinforced concrete PIO clarifier with a volume of $40,000 \mathrm{~m}^{3} / \mathrm{d}$. The main parameters are as follows: the design flow $\mathrm{Q}_{\max }=833.3 \mathrm{~m}^{3} / \mathrm{h}$, the design surface load $\mathrm{q}=1.04 \mathrm{~m}^{3} / \mathrm{m}^{2} \cdot \mathrm{h}$, the settling time HRT $=3.0 \mathrm{~h}$, the (effective) water depth at the edge $\mathrm{H}_{2}=4.3 \mathrm{~m}$, the total height 
$\mathrm{H}=5.4 \mathrm{~m}$ and the diameter $\mathrm{D}=32 \mathrm{~m}$. There are 100 distribution holes for peripheral inflow.

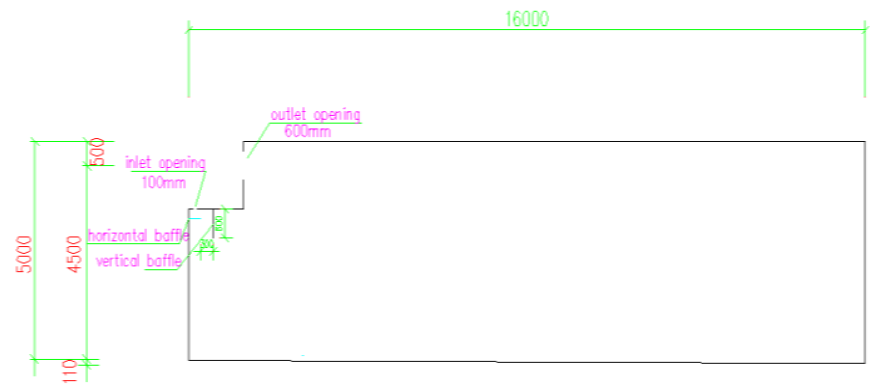

Figure 1. Profile of the CSC

As shown in Figure 1, a deflection baffle and a retaining baffle are arranged near the inlet of the PIO CSC. The deflection baffle, located right below the inflow channel, reduces the impact of the water flow and allows it to spread in the circumferential direction of the clarifier. This is because the inflow channel alone cannot realize the uniform inflow along the peripheral of the CSC. Considering the short distance between the inlet and outlet in the PIO CSC, the retaining baffle is adopted to create a clean water zone between the inlet zone and the outlet zone. With the retaining baffle, the water will flow slowly and evenly into the clarifier, spread outwards, and return to the peripheral inflow channel as a gentle circulation. Thus, the volume of the whole clarifier can be utilized to eliminate the flow short-circuiting.

Considering the geometric symmetry of the CSC, the 3D motion of the flow in the CSC was simplified as a 2D motion in the axial and radial directions. The circumferential flow was ignored to reduce the number of grids and shorten the computing time. It is also assumed that the inflow is uniform along the circumference. With the 2D axisymmetric model, the author attempted to disclose the effect of retaining baffle structure on the CSC when the deflection baffle remains the same.

\subsection{Simulation conditions}

In the CSC, the inflow rate was set to $0.05 \mathrm{~m} / \mathrm{s}$, the sludge volume fraction to 0.0034 , the sludge density to $1,118 \mathrm{~kg} / \mathrm{m}^{3}$, the sludge mass concentration (volume fraction $\times$ density) to $3.8 \mathrm{~kg} / \mathrm{m}^{3}$, and the average particle size to $120 \mu$. The inflow was defined by velocity inlet boundary conditions: the solidphase and liquid-phase share the same velocity; the velocity, turbulence kinetic energy and its dissipation rate are evenly distributed at the inlet profile. The supernatant outflow was described by the pressure outlet boundary conditions: the local pressure intensity is the outlet pressure intensity. The solid walls, i.e. the bottom and sidewalls (including the baffles) were illustrated by non-slip wall boundary conditions: the impact of roughness is determined by the wall function. The free surface was depicted by the symmetry boundary conditions. Then, the CSC was meshed into structured quadrilateral grids. The grids were refined and tested for independence. The results show that the 189,759 grids can meet the requirements of our numerical simulation.

\section{SIMULATION AND ANALYSIS}

In view of the main influencing factors of the sedimentation effect, the effect of retaining baffle structure on the sedimentation effect of the CSC was investigated mainly from the streamline distribution and sludge volume concentration.

\subsection{Impact of baffle distance on sedimentation effect}

The existing data showed that the distance between the retaining baffle and the deflection baffle (hereinafter referred to as the baffle distance) can control the flow velocity of the profile. The current baffle distance of the CSC was $300 \mathrm{~mm}$. To identify the effect of the baffle distance on sedimentation, five models with different distances were set up for simulation calculation. Specifically, the baffle distance in these models were set to $50 \mathrm{~mm}, 130 \mathrm{~mm}, 300 \mathrm{~mm}, 500 \mathrm{~mm}$ and $800 \mathrm{~mm}$, respectively, without changing the water depth. The inflow conditions are as specified in Section 4.2. Figures 2-3 below present the near-inlet streamline and sludge volume concentration at each baffle distance.

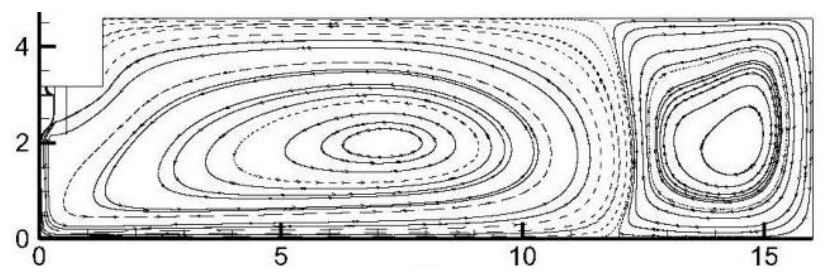

(a) Baffle distance of $50 \mathrm{~mm}$

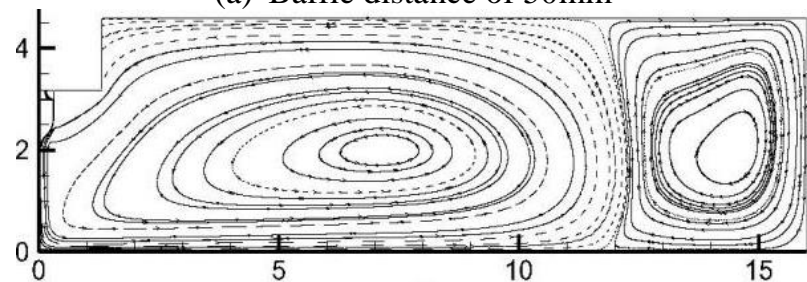

(b) Baffle distance of $130 \mathrm{~mm}$

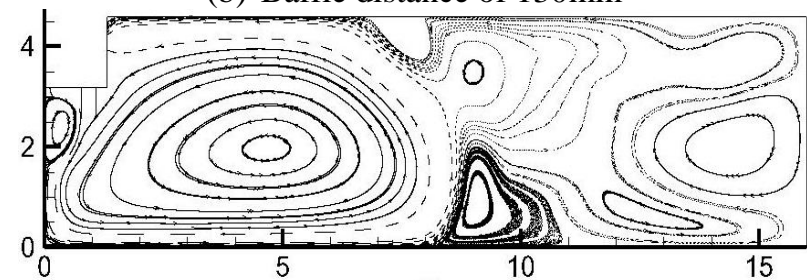

(c) Baffle distance of $300 \mathrm{~mm}$

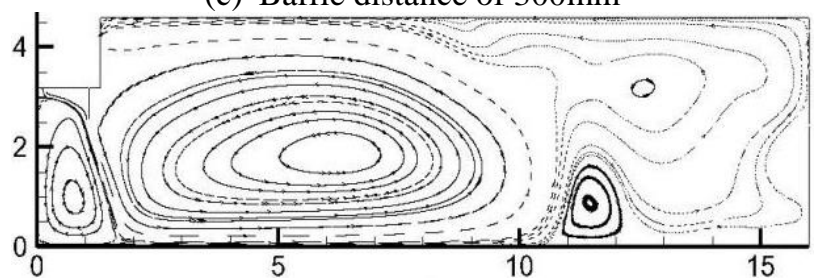

(d) Baffle distance of $500 \mathrm{~mm}$

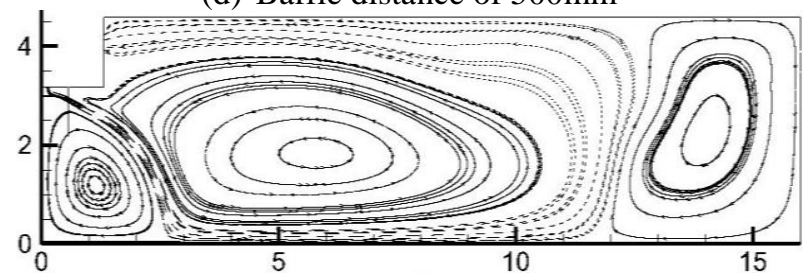

(e) Baffle distance of $800 \mathrm{~mm}$

Figure 2. Five different near-inlet streamlines 


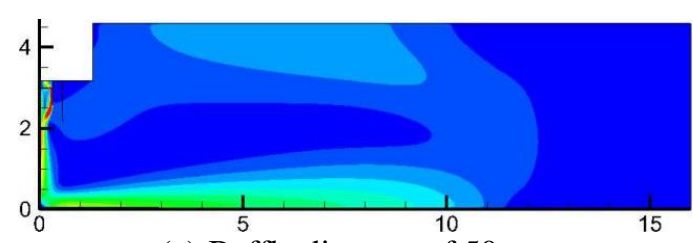

(a) Baffle distance of $50 \mathrm{~mm}$

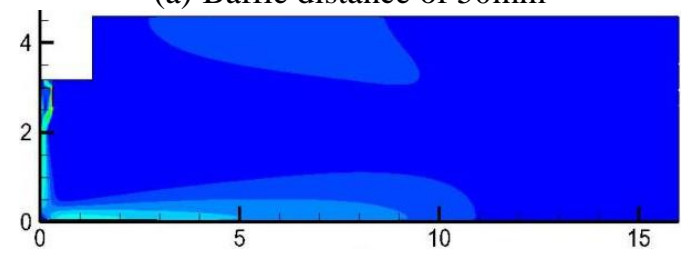

(b) Baffle distance of $130 \mathrm{~mm}$

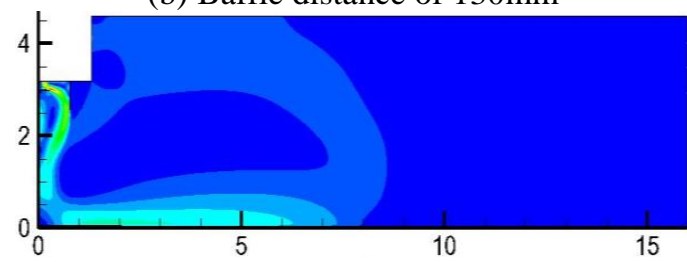

(c) Baffle distance of $300 \mathrm{~mm}$

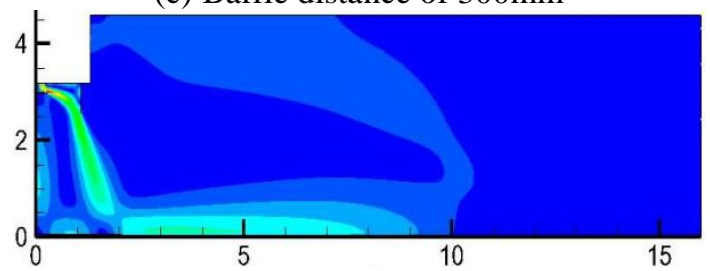

(d) Baffle distance of $500 \mathrm{~mm}$

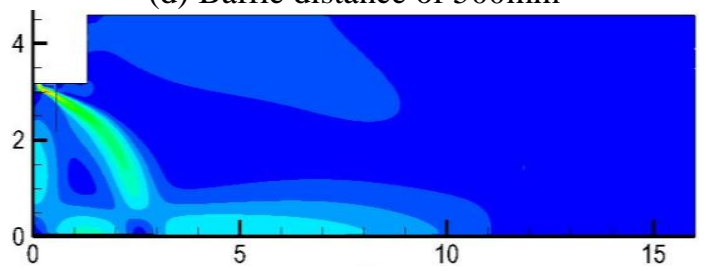

(e) Baffle distance of $800 \mathrm{~mm}$

Figure 3. Five different sludge volume concentrations Note: 1. The horizontal and vertical coordinates in Figures $2 \sim 3$ are all expressed in $\mathrm{m}$. 2. Reference diagram for the variation in sludge volume concentration:

Velocity Magnitude: 0.050 .10 .15020250 .2035040450 .050 .550 .6

The following conclusions can be drawn from Figures 2-3. (1) The streamline densities in the streamline diagrams reflect the magnitude of the flow velocity. In general, the density is positively correlated with the magnitude. Judging by the streamline density, it is learned that the flow velocity after the deflection baffle slowed down as the baffle distance widened from $50 \mathrm{~mm}$ to $300 \mathrm{~mm}$, and remained basically unchanged as the distance expanded from $300 \mathrm{~mm}$ to $500 \mathrm{~mm}$; when the distance reached $800 \mathrm{~mm}$, the retaining baffle could no longer block the water flow, and the latter moved over the deflection baffle and headed directly towards the center of the clarifier. (2) Focusing on the streamline from the deflection baffle, the bottom to the center of the clarifier, it is observed that the flow field underwent significant changes when the baffle distance grew from $50 \mathrm{~mm}$ to $300 \mathrm{~mm}$, and remained basically unchanged as the distance increased from 300 to $500 \mathrm{~mm}$; the streamline covered a much shorter distance between the inlet and the outlet, when the baffle distance reached $800 \mathrm{~mm}$. (3) With the gradual increase in the baffle distance, the interface between the clean water zone and the separation zone became shorter and shorter, and finally reached a stable height. Specifically, the interface height exhibited an obvious yet gradual decline as the baffle distance rose from $50 \mathrm{~mm}$ to
$300 \mathrm{~mm}$. The height and shape of the interface at the distance of $300 \mathrm{~mm}$ were almost the same with those at $500 \mathrm{~mm}$. The interface was unstable at the distance of $800 \mathrm{~mm}$. (4) To sum up, the increase in the baffle distance can effectively enhance the sedimentation efficiency and outflow quality, provided that the distance is relatively small; when the baffle distance is already large, any further increase of it can only achieve a slight enhancement, if not suppressing the sedimentation efficiency and outflow quality.

\subsection{Impact of retaining baffle depth on sedimentation effect}

Apart from controlling the inflow velocity, the retaining baffle can also create a clean water zone between the inlet zone and the outlet zone. To disclose the effect of retaining baffle depth on sedimentation, five more models with different retaining baffle depths were set up for simulation calculation. Specifically, the retaining baffle depths in these models were set to $200 \mathrm{~mm}, 400 \mathrm{~mm}, 600 \mathrm{~mm}, 1,000 \mathrm{~mm}$ and $1,500 \mathrm{~mm}$, respectively, without changing the baffle distance. Figures 45 below present the near-inlet streamline and sludge volume concentration at each retaining baffle depth.

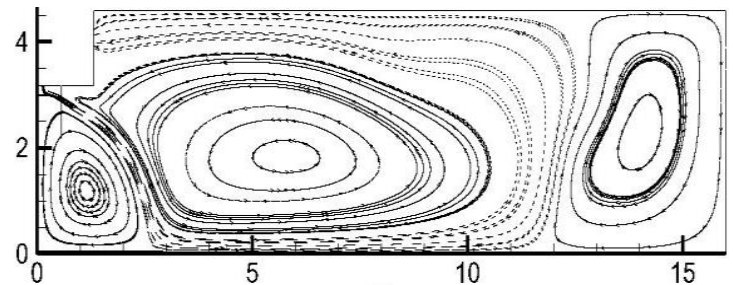

(a) Baffle depth of $200 \mathrm{~mm}$

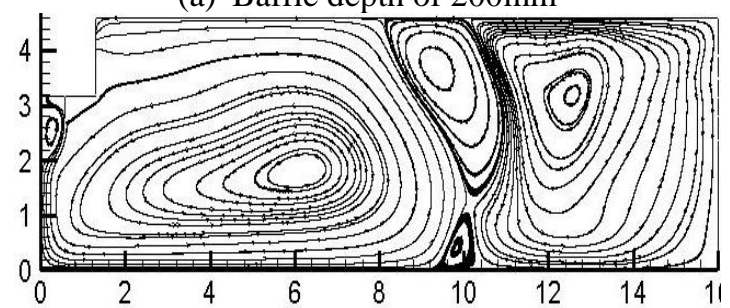

(b) Baffle depth of $400 \mathrm{~mm}$

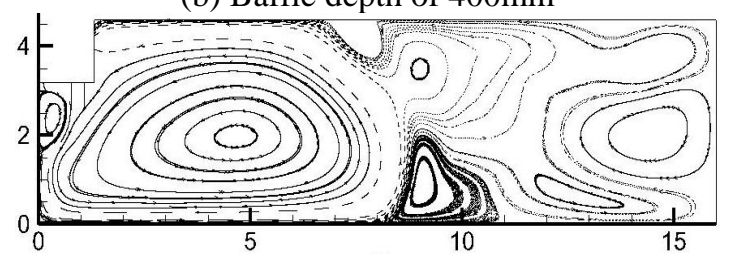

(c) Baffle depth of $600 \mathrm{~mm}$

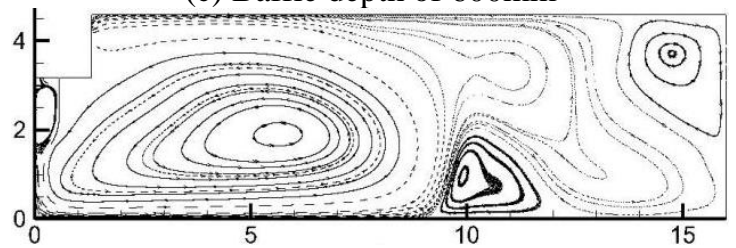

(d) Baffle depth of $1000 \mathrm{~mm}$

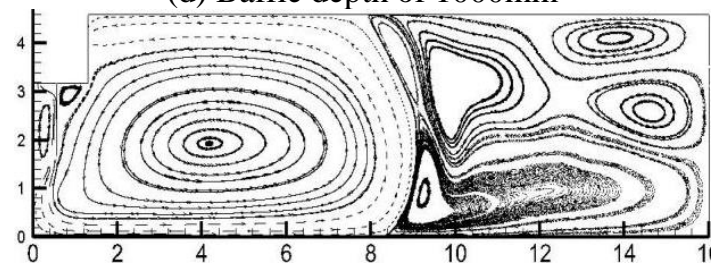

(e) Baffle depth of $1500 \mathrm{~mm}$

Figure 4. Five different near-inlet streamlines 


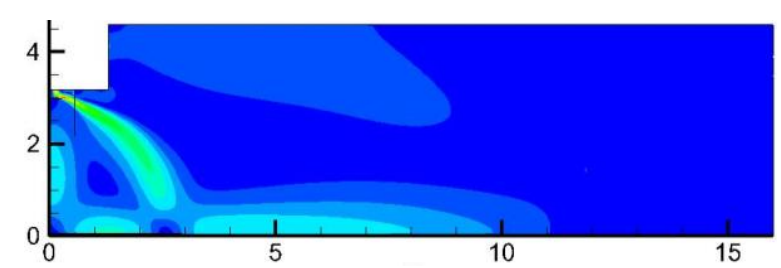

(a) Baffle depth of $200 \mathrm{~mm}$

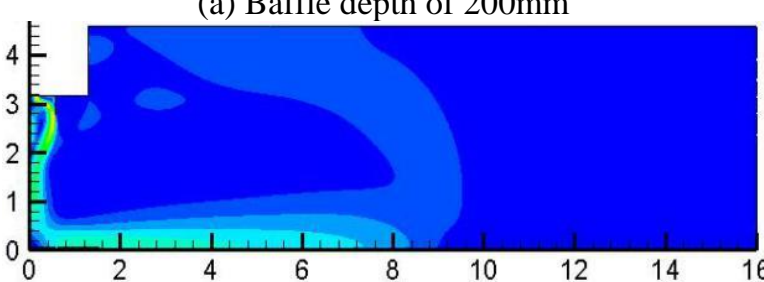

(b) Baffle depth of $400 \mathrm{~mm}$

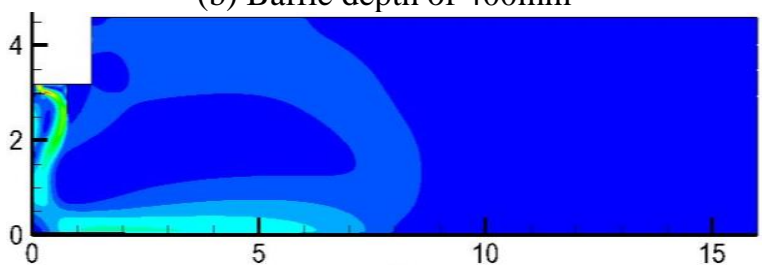

(c) Baffle depth of $600 \mathrm{~mm}$

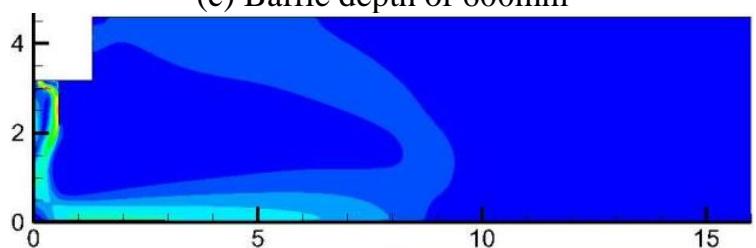

(d) Baffle depth of $1000 \mathrm{~mm}$

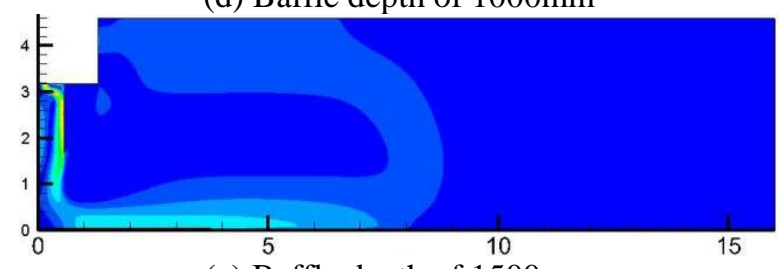

(e) Baffle depth of $1500 \mathrm{~mm}$

Figure 5. Five different sludge volume concentrations

The following conclusions can be drawn from Figures 4-5. (1) When there was no retaining baffle or only a shallow retaining baffle, the water flowed directly towards the center of the clarifier because the inlet zone was not effectively separated from the outlet zone. (2) With a depth between $400 \mathrm{~mm}$ and $1,000 \mathrm{~mm}$, the retaining baffle could sufficiently separate the inlet and outlet zones. In this case, the water flow always moved along the baffle towards the bottom of the clarifier, rather than change with the increase of the retaining baffle depth. (3) The retaining baffle depth directly bears on the interface between the clean water zone and the separation zone. The greater the depth, the lower the interface and the wider the clean water zone. (4) In summary, the outflow quality can be improved with the increase in the retaining baffle depth, provided that the depth is relatively small; once the depth surpassed $1,000 \mathrm{~mm}$, any further increase in the depth will result in a slightly worse outflow quality. In other words, increasing the retaining baffle depth within a certain range can effectively increase the sedimentation efficiency and outflow quality of the CSC; when the retaining baffle is already deep, it is neither effective nor economic to further increase the depth.

\section{CONCLUSION}

This paper numerically simulates the flow field variation and sludge migration in the PIO CSC. The trajectories of sludge and water in the flow field were simulated at different baffle distances at the inlet and different retaining baffle depths, with the aim to disclose the effect of the distance and depth on the flow field. The simulation results reveal that: the baffle distance has an impact on the sedimentation efficiency and outflow quality. The increase in the baffle distance can effectively enhance the sedimentation efficiency and outflow quality, provided that the distance is relatively small; when the baffle distance is already large, any further increase of it can only achieve a slight enhancement, if not suppressing the sedimentation efficiency and outflow quality. If there is a retaining baffle with a certain depth at the inlet, the reflux zone of the flow field will be reduced significantly, resulting in a larger effective flow zone. In this case, the clarifier can treat more sludge, operate for a longer cycle, and output cleaner water. In general, the outflow quality is rather poor when the retaining baffle is too shallow; however, the outflow quality can be improved with the increase in the retaining baffle depth; once the depth surpassed $1,000 \mathrm{~mm}$, any further increase in the depth will result in a slightly worse outflow quality. According to the simulation results, the optimal performance of the CSC appeared at the baffle distance of $300 \mathrm{~mm}$ and the retaining baffle depth of $600-1,000 \mathrm{~mm}$. All in all, a proper increase of distance and depth can enhance the sedimentation efficiency and outflow quality, but an excessive increase can only accomplish the very opposite.

\section{ACKNOWLEDGMENT}

The work described in this paper was fully supported by Scientific and Technological Research Projects of Hubei Provincial Department of Education (No. B2016007).

\section{REFERENCES}

[1] Roza T, Asterios P. (2013). CFD methodology for sedimentation tanks: The effect of secondary phase on fluid phase using DPM coupled calculations. Applied Mathematical Modelling 37(5): 3478-3494. https://doi.org/10.1016/j.apm.2012.08.011

[2] Roza T, Asterios P. (2014). The influence of lamellar settler in sedimentation tanks for potable water treatment--A computational fluid dynamic study. Powder Technology 268: 139-149. https://doi.org/10.1016/j.powtec.2014.08.030

[3] Ben L, Michael KS. (2014). Research advances and challenges in one-dimensional modeling of secondary settling Tanks-A critical review. Water Research 50: 160170. https://doi.org/10.1016/j.watres.2013.11.037

[4] Elham R, Dorottya SW, Lars Y, Philip JB., Michael RR, Peter SM., Benedek GP. (2014). A new settling velocity model to describe secondary sedimentation. Water Research 66: 447-458. https://doi.org/10.1016/j.watres.2014.08.034

[5] Estelle G, Elham R, Murat K, Benedek GP. (2015). ICFD: Interpreted Computational Fluid Dynamics $\mathrm{e}$ Degeneration of CFD to one-dimensional advectiondispersion models using statistical experimental design - 
The secondary clarifier. Water Research 83: 396-411. https://doi.org/10.1016/j.watres.2015.06.012

[6] Nicolas D, Christian T, David D, Kris V. (2017). Batch settling curve registration via image data modeling. Water Research 124: 327-337. https://doi.org/10.1016/j.watres.2017.01.049

[7] $\mathrm{Xu} \mathrm{G}$, Yin F, Xu Y, Yu H. (2017). A force-based mechanistic model for describing activated sludge settling process. Water Research 127: 118-126. https://doi.org/10.1016/j.watres.2017.10.013

[8] Raimund B, Stefan D, Sebastian F, Ingmar N. (2012). On reliable and unreliable numerical methods for the simulation of secondary settling tanks in wastewater treatment. Computers \& Chemical Engineering 41: 93105.

https://doi.org/10.1016/j.compchemeng.2012.02.016

[9] Elham R, Xavier FA, Gürkan S, Krist VG, Ulf J, Peter SM, Benedek GP. (2014). Influence of selecting secondary settling tank sub-models on the calibration of WWTP models-A global sensitivity analysis using BSM2. Chemical Engineering Journal 241: 28-34. https://doi.org/10.1016/j.cej.2013.12.015

[10] Patziger M. (2016). Computational fluid dynamics investigation of shallow circular secondary settling tanks: Inlet geometry and performance indicators. Chemical Engineering Research and Design 112: 122-131. https://doi.org/10.1016/j.cherd.2016.06.018

[11] Zahir B. Derradji C, Saci N. (2012). Dynamic modelling of the secondary settler of a wastewater treatment via activated sludge to low-load. Energy Procedia 18: 1-9. https://doi.org/10.1016/j.egypro.2012.05.012

[12] Qin B. (2012). Research on domestic wastewater treatment with radial flow inclined tube settling tank. Environmental Science and Management 37(4): 82-85.

[13] Liu YL, Zhang P, Wei W. (2013). Two-dimensional numerical simulation of properties of liquid-solid two- phase flow in a circular secondary clarifier. Engineering Journal of Wuhan University 46(4): 410-412.

[14] Liu YL, Zhang P, Wei WL. (2013). Numerical simulation of mechanical property of solid-liquid twophase turbulent flow in a secondary sedimentation tank of radial flow. Journal of Water Resources \& Water Engineering 24(4): 25-27.

[15] Wei WL, Li PP, Hong YF, Liu YL. (2016). Influence of baffle length on flow and sludge concentration fields in a radial sedimentation tank. Journal of Northwest A\&F University (Nat. Sci. Ed.) 44(7): 228-234. https://doi.org/10.13207/j.enki.jnwafu.2016.07.032

[16] Wei WL, Bai CW, Liu YL. (2016). 3D simulation for the influence of a feed baffle on the density current behaviors caused by temperature in a radial sedimentation tank. Journal of Xi'an University of Technology 32(1): 12-17. https://doi.org/10.19322/j.cnki.issn.10064710.2016.01.003

\section{NOMENCLATURE}

$\begin{array}{ll}\mathrm{F} & \text { force } \\ \mathrm{g} & \text { gravitational acceleration, } \mathrm{m} \cdot \mathrm{s}^{-2} \\ \mathrm{n} & \text { phase number } \\ \mathrm{P} & \text { pressure, } \mathrm{Pa} \\ \mathrm{v} & \text { velocity, } \mathrm{m} / \mathrm{s}\end{array}$

\section{Greek symbols}

$\begin{array}{ll}\rho & \text { density, } \mathrm{kg} / \mathrm{m}^{3} \\ \varepsilon & \text { dissipation rate, } \mathrm{J} / \mathrm{kg} \cdot \mathrm{s} \\ \mu & \text { mixture viscosity, } \mathrm{kg} \cdot \mathrm{m}^{-1} \cdot \mathrm{s}^{-1} \\ \eta & \text { viscosity coefficient, } \mathrm{kg} \cdot \mathrm{m}^{-1} \cdot \mathrm{s}^{-1}\end{array}$

